\title{
DESIGN E ERGONOMIA: BASES DE IDENTIFICAC̣ÃO DE DEMANDAS
}

Design and Ergonomics: Demands Identification Bases

\section{ALANO, Agda Bernardete I Mestranda em Design e Expressão Gráfica/UFSC \\ Universidade Federal de Santa Catarina - UFSC I agda.alano@gmail.com}

\section{FIGUEIREDO, Luiz Fernando I Doutor em Engenharia de Produção}

Universidade Federal de Santa Catarina - UFSC I Iff@cce.ufsc.br

\section{MERINO, Eugenio Andrés Díaz I Doutor em Engenharia de Produção}

Universidade Federal de Santa Catarina - UFSC I merino@ufsc.br

\section{MERINO, Giselle Schmidt A. Díaz I Doutora em Engenharia de Produção}

Universidade Federal de Santa Catarina - UFSC I gisellemerino@gmail.com

\section{Resumo}

Este artigo apresenta a análise ergonômica de trabalho em uma comunidade criativa que tem como atividade a tecelagem de tapetes em teares manuais. Considerouse na análise ergonômica o processo a partir da interação do operador com o tear, na qual o design participa por meio da representação projetual do sistema que envolve a situação de trabalho. Por meio de uma metodologia de análise ergonômica, este estudo apresenta o diagnóstico de demandas existentes e apresenta como proposta de melhoria um projeto incremental no posto de trabalho, visando contribuir com a qualidade de vida de artesãs levando seu contexto sociocultural.

\section{Abstract}

This article presents the ergonomic analysis of work in a creative community that is engaged in carpet weaving on handlooms. The ergonomic analysis started from the user interaction with the loom, in which the design acts through the representation of the system involving the work situation. Through a methodology of ergonomic analysis, this study presents the diagnosis of existing demands and proposes an improvement in the workplace, in order to contribute to the quality of life of artisans bringing to it their sociocultural context.

Keywords: Ergonomics. Design. Creative Community.

Palavras-chave: Ergonomia. Design. Comunidade Criativa. 


\section{INTRODUÇÃO}

A exposição aos fatores de risco presentes nas condições de trabalho tem contribuído para a ocorrência, cada vez mais frequente, de doenças físicas em trabalhadores de diferentes atividades econômicas. Dentre elas, destacam-se os problemas ligados aos distúrbios osteomusculares relacionados ao Trabalho (DORT).

Os dados estatísticos do Health and Safety Executive Ex $^{5}$ mastram que no ano de 2012 doenças ocupacionais na indústria têxtil foram responsáveis pelo afastamento de 314.000 mil trabalhadores no mundo. De acordo com Simpson (1994 apud STANTON, 2003) com base nos dados do Health and Safety Executive, 90 por cento dos acidentes de trabalho são causados em parte por erro humano. Estes podem ser causados diretamente pela tarefa manual ou por erro ou violação do procedimento.

Diante deste cenário, a análise da exposição aos fatores de risco ergonômicos evidencia a necessidade da identificação de possíveis causas.

Este estudo relaciona o design e a ergonomia na apresentação de soluções que possam melhorar a qualidade de vida de operadores de tear, a partir da análise ergonômica em uma comunidade criativa produtora de tapetes artesanais.

Diferente de um modo de produção seriada, este tipo de empreendimento requer uma análise que possibilite o diagnóstico de possíveis melhorias na realização da tarefa sem que afete aspectos culturais. Assim, são considerados na relação com a ergonomia, aspectos ligados à usabilidade, nos quais o design participa na identificação e representação de sistemas de interação entre operador e os demais elementos com compõem o posto de trabalho a fim de facilitar o levantamento de hipóteses durante uma análise de demanda ergonômica para que, como resultado seja apresentado propostas de melhorias incrementais a fim de melhorar a qualidade de vida no trabalho.

\section{Contexto social comunidade criativa}

Neste estudo análise ergonômica do trabalho é determinada, a partir da tecelagem manual de tapetes em uma comunidade criativa, analisada com base em fatores técnicos e humanos existentes, determinados pelas atividades dos operadores de tear.

\section{O termo comunidades criativas pode ser definido como grupos de pessoas}

$5 \quad$ Health and Safety Executive: É um organismo público responsável pelo incentivo, regulação e aplicação da saúde, segurança e bem-estar no trabalho do Reino Unido, com sede em Liverpool.

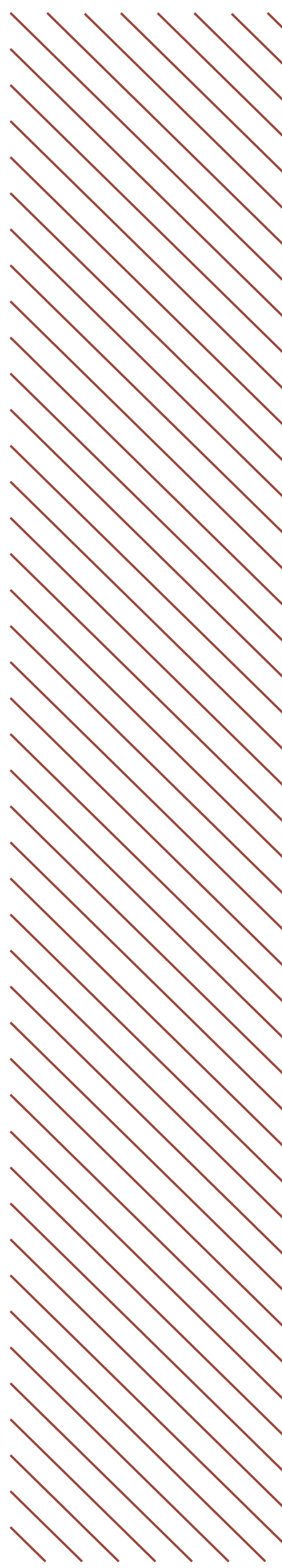


que se organizam por iniciativa própria, para transformar as suas comunidades em locais melhores para viver, trabalhar, aprender, interagir e resolver problemas socioambientais. Criam pequenas contribuições que se antecipam a grande mudança necessária para a sociedade reorientar-se para a direção da sustentabilidade. Manzini (2008) define comunidade criativa como:

"[...] modos de vida em comum, nos quais espaços e serviços são compartilhados; atividades de produção baseadas nas habilidades e recursos de uma localidade específica, mas que se articula com as mais amplas redes globais [...]" (MANZINI, 2008).

Este estudo trata a partir de um estudo de caso da comunidade "TOCA TAPETES" que se caracteriza como uma comunidade de mulheres que trabalham na tecelagem de tapetes.

A criação do tecido do tapete é feito a partir do entrelaçamento entre o fio de algodão e as tiras de tecido são acomodadas em dois sentidos, no urdume ou urdidura. É formado por um conjunto de fios tensos colocados em paralelo previamente no sentido do comprimento do tear que servirão de suporte para o conjunto de tiras de tecido colocados no sentido oposto, caracterizando-se a como a trama do tecido do tapete.

Diferente da tecelagem convencional, a tecelagem de tapetes a trama é formada por tiras de tecido, ao invés de fios, e a sua passagem por entre a abertura (cala) é feita de forma manual com um novelo de tiras no lugar da lançadeira.

Esse tipo de tecelagem constitui uma estrutura simples, na qual o resultado do entrelaçamento lembra um tabuleiro (GOMES FILHO, 2006), que resulta no tapete, a partir da combinação de fios e tiras, o que permite uma diversificação nos aspectos formais, tornando-se infinitamente diversa e exclusiva, proporcionado pelo resíduo têxtil que varia em cores e texturas.

\section{Dimensões sociais do trabalho em comunidades criativas}

Comunidades criativas representa um tipo de empreendimento que se difere dos atuais modelos econômicos, para se perceber isso, é necessário olhar não somente para o valor de uma comunidade, apenas pelo produto do seu trabalho, mas para o processo, que pode ser considerado, a partir do seu significado enquanto forma de integrar pessoas em busca de objetivo comum.

A psicologia social sustenta que nos países ricos, apesar da pressão materialista, o bem-estar subjetivo está relacionado a uma crença nas relações interpessoais: a capacidade de unir pessoas em torno de uma ideia, de levar 
as pessoas em movimento, para se reunir em prol de uma questão; todas são características que são claramente expressas pelas comunidades criativas (MERONI, 2007, p.10).

Segundo Carli et al. (2001), "o artesanato é uma das mais tradicionais formas de manifestação cultural, mas, como tudo que atravessa o tempo, precisa se renovar de alguma maneira". E, assim considera-se a necessidade de adaptar-se, não somente pelo ponto de vista técnico, mas levar em conta questões sociais, a ponto que melhore o trabalho e a vida do artesão.

Krucken (2009) corrobora dizendo que é necessário promover soluções inovadoras e sustentáveis, que aproximem produtores e consumidores, dando transparência e fortalecendo os valores que perpassam a produção e o consumo". Tais considerações são importantes e devem ser levadas para dentro da organização de forma a dar para aqueles que participam do processo condições eficazes e qualitativas para a que solução seja vista não somente a partir do resultado em produto, mas pelo modo de vida que participa do processo.

O trabalho artesanal como atividade em comunidades criativas, constitui como importantes meios de geração de economia para um determinado local, além de representar uma constante reinvenção de tradições, o que torna a comunidade representativa pelo seu valor cultural.

Meroni (2007) refere-se ao trabalhador de comunidade criativa como um herói que integra valores como o respeito ao meio ambiente, consumindo menos gerando assim sociabilidade, uma vez que usa recursos de forma eficiente assim criando laços de solidariedade em todos os sentidos, não somente em termos de geração de valor para si, mas de modo coletivo, valorizado pela experiência que o trabalho pode trazer.

O valor expressado pelo trabalho artesanal de uma comunidade é representativo não somente enquanto empreendimento econômico, mas pela sua expressão cultural. Segundo Krucken (2009) tornar visíveis os valores relacionados com um produto local, com respeito a seus recursos e o conhecimento incorporado na sua produção e a sua importância para a comunidade produtora é uma forma de contribuir para tornar visível à sociedade à história por trás do produto.

Assim o trabalho artesanal em comunidades criativas é muito mais que uma forma de geração de economia, portanto o trabalho deve ser visto nesses casos muito além de aspectos técnicos. 


\title{
Dimensões da ergonomia no trabalho
}

Segundo a definição da International Ergonomics Association (2014), ergonomia é a disciplina científica que trata das interações entre os seres humanos e outros elementos de um sistema, é a ciência que aplica teorias, princípios, dados e métodos a projetos que visam melhorar o bem-estar humano e a performance global dos sistemas. Ainda segundo a International Ergonomics Association (2014):

\begin{abstract}
A ergonomia é o estudo científico da relação entre o homem e seus meios, métodos e espaço de trabalho. Seu objetivo é elaborar, mediante a contribuição de diversas disciplinas científicas que a compõem, um corpo de conhecimentos que, dentro de uma perspectiva de aplicação, deve resultar numa melhor adaptação ao homem dos meios tecnológicos e dos ambientes de trabalho e de vida.
\end{abstract}

Pode-se afirmar que a ergonomia e o design têm muito a contribuir com a interação de humanos e os outros elementos de um sistema, pois de um lado segundo Bonsiepe e Dutra (1997) a ergonomia trata da interação entre pessoas, usuários, consumidores, operadores; que constituem como conhecimento importante para a o design. Essa compreensão permite ao design a concepção projetual eficaz para uma melhor adaptação do homem e seus meios. Pelo ponto de vista do produto segundo Landim (2010) "o design agrega valor em termos de estética, enquanto que a ergonomia confere conforto e funcionalidade [além] de ser um elemento muito importante na racionalização da produção".

A ergonomia do ponto de vista da ciência que estuda o homem no trabalho segundo alguns autores é a relação homem-trabalho analisada segundo um modelo antropocêntrico; no qual de um lado o homem ou homens e, de outro lado às tarefas que ele deve efetuar (SANTOS; FIALHO, 1995). No lado da tarefa, considera-se; ex: as máquinas, ferramentas e a matéria prima e ação; e de outro lado o homem a partir da sua relação com o meio ambiente de trabalho, onde a informação pode nesta relação ser compreendida a partir da interação bem sucedida entre o homem e a tarefa a ser realizada. 
Figura 1- Tarefa - Homem

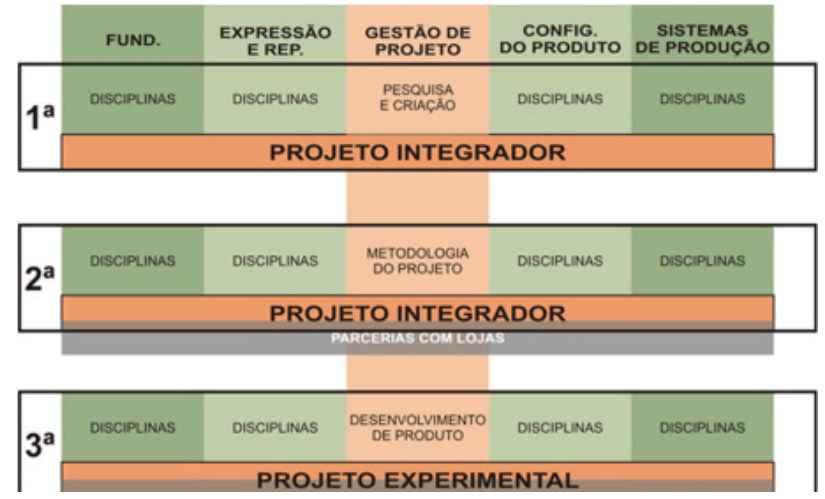

Fonte: Adaptada de Santos e Fialho (1995).

De acordo com o modelo apresentado por Santos e Fialho (1995) evidenciam-se as principais condicionantes que afetam o desenvolvimento das atividades do homem no trabalho, como:

- Má concepção dos meios materiais do trabalho (informações);

- Exigências em termos de trabalho muscular (objetos, ferramentas, comandos, etc.);

- Características ambientais;

- Condicionantes temporais (cadência, duração e horário);

- Organização do trabalho (hierarquia, turnos, equipes, métodos, comunicação);

- Ambiente psicossociológico;

- Condições de vida extraprofissional. (SANTOS; FIALHO, 1995).

No passado pouca atenção era dada ao trabalho com respeito às necessidades humanas e a falta de segurança. Após a revolução industrial iniciou-se uma reflexão epistemológica onde o debate sobre a ergonomia se tornaram comuns, bem como a outras disciplinas que tratam do ser humano na sua relação com o trabalho. (PIZO; MENEGON, 2010).

De acordo com Merino (2011) é necessário para o desenvolvimento de organizações saudáveis, que os seres humanos sejam vistos como indivíduos saudáveis, respeitando e contribuindo com a qualidade de vida no trabalho.

Assim a saúde e qualidade de vida do trabalhador propiciam um ambiente saudável, no qual a ergonomia se insere de acordo com os princípios de equidade social, a partir da visão de que "trabalhadores devem ser considerados como seres integrais, contribuindo para que o trabalho seja visto e tratado de uma forma mais humana" (MERINO, 2011).

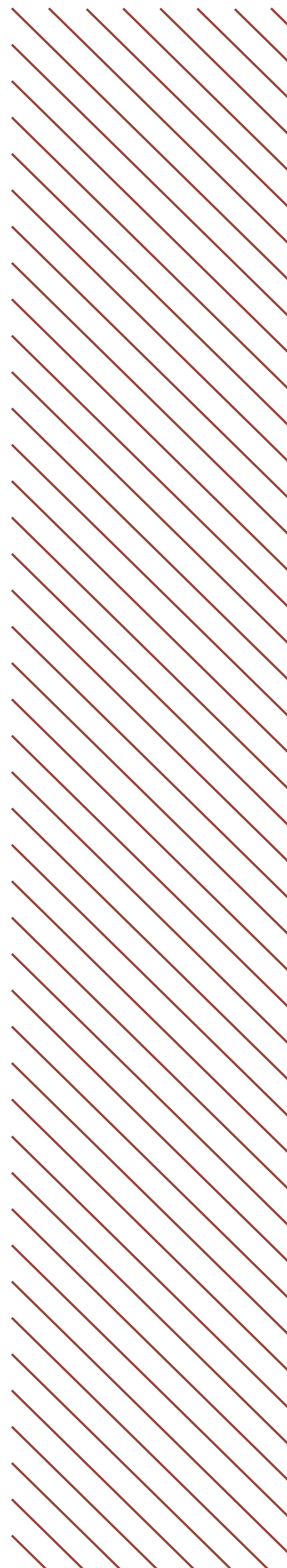


Levando em conta o trabalho como valor, não somente pelo ponto de vista econômico, mas como forma de garantir ao trabalhador de inserir-se socialmente, a implicação de responsabilidade se amplia em diferentes questões que no âmbito de um pensamento socioético e vincula-se ao que a Organização das Nações Unidas (1992) define, a partir dos princípios e regras da democracia, dos direitos humanos [...] e [assim o trabalho como uma forma de proporcionar a] de redução da pobreza; a ampliação do acesso à informação, capacitação e emprego; o respeito à diversidade cultural, identidades e biodiversidade.

Santos e Fialho (1995, p.25) pontuam que "o trabalho é uma forma de atividade própria do homem, enquanto ser social". O que segundo Merino (2011) "a atividade humana seja no trabalho ou no lazer, afeta diretamente as condições de vida (grifo do autor) (habitação, transporte, educação, saúde, dentre outras)". Assim, o trabalho é uma atividade humana que nos insere em uma sociedade, dando um significado social pelo resultado do que se produz e pela forma como se relaciona com o meio.

Oportunizar o trabalho de forma justa e igualitária corresponde ao que define a Estratégia para o Desenvolvimento Sustentável da União Européia (CONSELHO NACIONAL DO AMBIENTE E DO DESENVOLVIMENTO SUSTENTÁVEL, 2006) quando relaciona essas questões à equidade e coesão social como formas de promover "uma sociedade democrática, socialmente inclusiva, coesa, saudável, segura e justa, que respeita os direitos fundamentais e a diversidade cultural, promove a igualdade de oportunidades [...]". A comunidade criativa enquanto um sistema, tem o trabalho como energia vital, que nutre-se com os desafios, oportunidades que um ambiente de criatividade e compartilhamento de ideias pode oportunizar.

\section{Abordagem sistêmica da ergonomia}

“Do ponto de vista da ergonomia, pode se dizer que, um sistema é um conjunto de componentes: homem, tecnologia, organização e meio ambiente de trabalho[...]", porém se levada à abordagem sistêmica segundo Bertalanffy (2008), "os elementos de um sistema constituem o todo, que não se reduz à soma das partes". Esta definição adquire identidade quando, consideramos o sistema enquanto um organismo vivo, onde a sua unidade e vitalidade dependem das competências e capacidades de seus elementos e da forma como interagem; que do ponto de vista da ergonomia esta interação é tratada partir do trabalho; onde seus "os componentes, as relações e os objetivos, constituem aspectos fundamentais na delimitação de um sistema" (SANTOS; FIALHO, 1995).

O sistema pode ser compreendido enquanto uma organização, bem como a partir de subsistemas como um posto de trabalho, que segundo Santos e Fialho (1995) "uma situação de trabalho é um sistema complexo e dinâmico", onde a entrada 
do sistema (input) corresponde às exigências do trabalho e, por conseguinte determinam a atividade do trabalhador (comportamento de trabalho) e, suas saídas (output) correspondem ao resultado do trabalho (figura 2).

Figura 2- Homem-Máquina

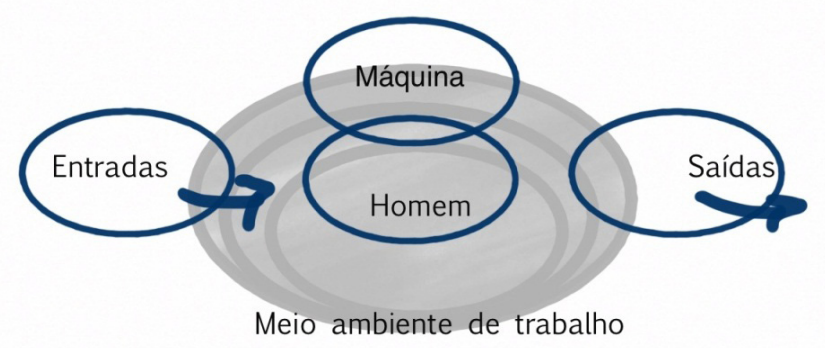

Fonte: Adaptada de Santos e Fialho (1995).

Assim podemos considerar um subsistema como um posto de trabalho (sistema homem-máquina); bem como como um sistema organização, como uma comunidade criativa, onde as trocas (input - trabalho - output); servem de base operatória para projetos em design onde o sistema em análise é comparado às qualidades complexas de sistemas naturais.

\section{Comunidades criativas enquanto um sistema aberto}

Enquanto um sistema aberto, comunidades criativas adquirem legitimidade a partir de suas trocas, onde aspectos sociais constituem valores adquiridos pelo comportamento humano, respondendo às variáveis que se encontram além se suas fronteiras, como o contexto social, político, econômico e ambiental.

Porém é necessário identificar componentes capazes de facilitar suas trocas, onde bases interdisciplinares possam atuar na facilitação da comunicação desse sistema (design- gestão de design), partindo da compreensão dos subsistemas (ergonomia), onde trabalhando juntos podem atingir um objetivo comum.

A ergonomia e o design como forma de contribuir com a qualidade de vida do homem e sua relação com o sistema deve preservar aspectos culturais como forma de promover o equilíbrio em sistemas produtivos, nos quais o trabalho constitui-se como valor, tanto pelo ponto de vista econômico, como pelo ponto de vista sociocultural.

A ergonomia fornece elementos capazes de compreender a interação entre pessoas, tecnologia e a organização (RODRIGUES; MERINO; CASAROTTO FILHO, 2013), onde ações ergonômicas veem de forma significativa contribuir com a inovação seja no processo produtivo, bem como gerar qualidade de vida 
para o trabalhador.

A ergonomia fornece a gestão de design uma metodologia capaz de compreender o sistema a partir do trabalho onde a partir dele é possível organizar e estruturar ações. Segundo (GUÉRIN et al., 2001) podemos relacionar a atividade de trabalho como uma função integradora do homem com a empresa.

Martins e Merino (2011) apontam a ergonomia como uma ferramenta integradora das funções operacionais, seja em casos de grandes ou pequenas organizações; por conseguinte a análise do trabalho, que possibilita não somente melhoria dos aspectos técnicos relacionados a ganho em produtividade, mas o aumento da qualidade de vida do trabalhador, que em termos de relação do homem com seu ambiente de trabalho.

Assim a análise ergonômica do trabalho pode ser compreendida a partir de sistemas homem(s)-máquina(s) onde de acordo com (SANTOS; FIALHO, 1995), consideram como um sistema formado por um posto de trabalho (exemplo: um digitador e um terminal de computador). A partir dessa relação é possível identificar a forma de interação humana com um determinado sistema proposto e relaciona-lo com os elementos constituintes desse sistema, assim considerando-se o meio, recursos e formas de interação.

De acordo com Dul e Weerdmeester (2004):

A ergonomia pode contribuir para solucionar um grande número de problemas sociais relacionados a saúde, segurança, conforto e eficiência [onde] a ocorrência de acidentes pode ser reduzida quando se consideram adequadamente as capacidades e limitações humanas e as características do ambiente.

\section{A usabilidade no trabalho}

Muitas situações de trabalho são prejudiciais à saúde levando o trabalhador a contrair doenças musculoesqueléticas, como também doenças psicológicas (DUL; WEERDMEESTER, 2004) que levam ao absenteísmo e a incapacitação ao trabalho.

Um projeto adequado do ambiente de trabalho, bem como dos equipamentos, constitui como uma forma de evitar tais problemas, proporcionando qualidade no trabalho, melhorando o clima motivacional da organização, o que gera aspectos qualitativos também pelo ponto de vista econômico. 
A ergonomia que lida com a interação humana por meio das atividades físicas relaciona em uma situação de trabalho a anatomia humana, antropometria, fisiologia e a biomecânica (International Ergonomics Association), leva em conta na relação com o trabalho, o manuseio de materiais, movimentos repetitivos, distúrbios musculoesqueléticos, que constituem como tópicos relevantes para projetos de postos de trabalho.

Tais fatores podem ser tratados pela ergonomia como questões relativas a usabilidade.

Moraes (2001) aponta como adequação, a usabilidade, a partir de um determinado contexto considerando-se assim o desempenho, onde em um posto de trabalho, a usabilidade pode ser relacionada ao uso eficaz de ferramentas, máquinas.

Stanton e Barber (1996), delimitam a usabilidade a partir dos seguintes fatores:

- facilidade na aprendizagem do uso;

- efetividade no desempenho;

- custos humanos aceitáveis (fadiga, estresse, desconforto);

- flexibilidade nas tarefas;

- utilidade percebida do produto;

- adequação às tarefas;

- atendimento às caracterizações das tarefas;

- atendimento às caracterizações dos usuários.

Existem órgãos responsáveis em regulamentar e normatizar postos de trabalho, equipamentos, máquinas; que oferecem aos profissionais responsáveis (ergonomistas, designers, engenheiros e outros) um conjunto de conhecimentos para à adequação ergonômica do trabalho.

A International Standardization Organization (ISO) é uma delas e atua como órgão internacional na certificação de empresas que define usabilidade como "a eficácia, eficiência e satisfação com que usuários específicos podem alcançar objetivos específicos em ambientes particulares". (ISO DIS 9241-11 apud JORDAN et al., 1996).

Na Europa também está representada pelo ComitéEuropéen de Normalisation (CEN), nos Estados Unidos a American National Standards Institute- ANSI e a inglesa, British Standards (BSI).

No Brasilexiste a Norma Regulamentadora NR $17^{6}$ do Ministério do $6 \quad$ NR 17 - Ergonomia, Portaria n 3.214, de 8.6.1978 do Ministério do Trabalho, modificada 
Trabalho que visa estabelecer parâmetros que permitam a adaptação das condições de trabalho às características psicofisiológicas dos trabalhadores, de modo a proporcionar um máximo de conforto, segurança e desempenho eficiente. Esta norma aponta tópicos relacionados ao ambiente de trabalho, postura do trabalhador, mobiliário, iluminação, níveis de ruído, temperatura, umidade, dimensões do espaço de trabalho e equipamentos. Levando em conta a adaptação psicofisiológicas de acordo com a natureza do trabalho a ser executado.

\section{MATERIAL E MÉTODO}

Para Análise Ergonômica do Trabalho - AET utilizou-se o método da ergonomia que compreende um conjunto de análises globais e sistemáticas que permitem a descrição e representação de uma situação de trabalho.

Este artigo apresenta a aplicação da etapa de Instrução/construção de demanda, que se constitui como uma das etapas da metodologia da Análise Ergonômica do Trabalho - AET (GUÉRIN et al., 2001).

De acordo com Guérin et al. (2001) o processo de construção de demanda se elabora ao longo do desenrolar da ação. Cada ação é, portanto singular. Existe, todavia um conjunto de pontos importantes que vão estruturar a construção da ação ergonômica. Segundo o autor, após o primeiro contato com os operadores envolvidos, o pesquisador fará as observações abertas. O que permitirá que o pesquisador formule hipóteses para que delas possa retirar elementos de resposta às questões colocadas.

Uma forma de começar uma análise ergonômica, segundo (GUÉRIN et al., 2001, p. 85) é compreender o funcionamento da empresa, para isso é necessário que além da análise entre o trabalhador e seu ambiente de trabalho, se conheça o contexto da organização.

O esquema a seguir (figura 3) demonstra um conjunto de pontos importantes que devem ser levados em conta para uma análise ergonômica do trabalho (AET), onde neste estudo foram úteis para orientar na construção de demandas na comunidade criativa TOCA TAPETES. 
Figura 3- Esquema metodológico da análise ergonômica do trabalho

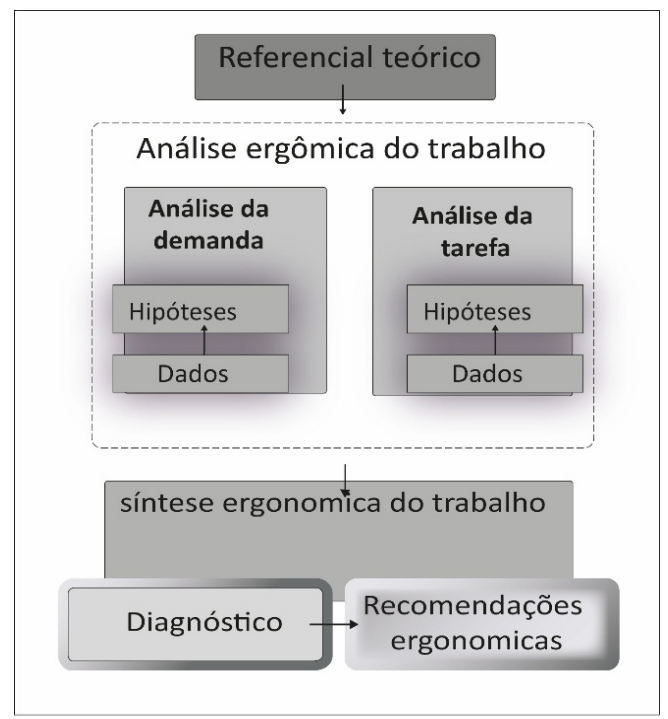

Fonte: Adaptado de Santos e Fialho (1995) e Guérin et al. (2001).

\section{A construção de demandas}

Foi utilizado o método de construção das demandas, iniciando-se a partir da análise do contexto da comunidade criativa "TOCA TAPETES", no qual o pesquisador teve como possibilidade de análise, o uso de técnicas interacionais com base na ação conversacional, escuta às verbalizações espontâneas e provocadas; bem como o uso de recursos técnicos auxiliados por filmagens, fotografias e de uma entrevista semiestruturada. Foram analisados cinco postos de trabalho de tecelagem, onde foram levadas em conta as exigências em termos de trabalho muscular (objetos, ferramentas, comandos, etc.); características ambientais e condicionantes temporais (cadência, duração e horário).

\section{Quadro 1- Comunidade Criativa TOCA TAPETES.}

\section{Comunidade Criativa que transformam resíduos têxteis tapetes: Toca tapetes}

\section{A solução}

TOCA TAPETESé uma comunidade criativa formada por um grupo de 55 mulheres que trabalham na produção de tapetes artesanais. Localizada a $12 \mathrm{~km}$ do centro urbano Araranguá (Santa Catarina) lá vivem pessoas que descobriram na arte da tecelagem de tapetes uma forma de garantir emprego e renda.

\section{O Contexto}

O trabalho no início era realizado de forma ainda mais rudimentar, pois os fios que faziam a trama do tapete eram feitos a partir do reaproveitamento de fios descartados do cultivo de fumo, o que tornava o processo mais árduo e demorado. Com o passar do tempo o trabalho foi se aprimorando, ampliando seu comércio e consequentemente a sua produção. 


\section{Situação Hoje}

Hoje a comunidade criativa TOCA TAPETES é administrada por três sócias que distribuem a produção para as artesãs, que são remuneradas a partir da produtividade.

O produto é vendido em lojas, feiras e exposições e os recursos obtidos garantem o emprego de mulheres que contribuem com a renda familiar.

\section{Valor Social}

Como valor social destaca-se a qualidade de vida do trabalho que se difere de modelos que tem como foco a alta produtividade, sendo que o trabalho é realizado sem que a mulher se ausente da presença da família e de seu espaço rural, podendo usufruir da forma simples, da vida no campo.

\begin{abstract}
Valor ambiental
Esse tipo de organização oferece também soluções ambientais, que são representadas pela forma de produção, característica de um trabalho artesanal e não existe em nenhuma parte do processo produtivo qualquer impacto ambiental. Ainda utiliza recursos materiais que seriam descartados pela indústria têxtil.
\end{abstract}

Fonte: Elaborado pelos autores, 2014

\section{Análise ergonômica do trabalho}

A partir da análise de contexto foi possível delimitar o processo técnico e das tarefas que para uma AET - Análise ergonômica do trabalho da tecelagem, onde foi escolhido como amostra intencional, o posto de trabalho de uma das artesãs que compõe a comunidade, que se constitui como uma situação de trabalho a ser considerada de acordo com metodologias de análise ergonômica.

A partir da definição da situação de trabalho a ser investigado foram levantadas hipóteses para que em confronto com o referencial teórico, pudessem evidenciar demandas necessárias que de acordo com (SANTOS; FIALHO, 1995; SALDANHA et al., 2012) constitui-se com uma forma de iniciarse uma abordagem para identificação de demanda.

A partir da delimitação da situação de trabalho foram considerados, de acordo com Paschoarelli e Menezes (2010) à quantidade de recursos disponíveis, material, o tipo de interação do produto, assim foi destacado na análise em uma estação de trabalho, o operador na relação com o espaço e artefatos para a realização da tecelagem.

\section{Tecelagem manual}

O tear manual (figura 4) ocupa uma área aproximada de 1,30m $\times 1,50$ $X 0,80$. Sua estrutura e formada por um cavalete de madeira que sustenta a mesa, o quadro de liços, o pente e dois rolos, um dianteiro com o fio de urdume e outro abaixo do tear com o tapete tecido.

Descrição da tarefa: Fazendo pressão nos pedais, o quadro de liços sobe 
e desce para separar os fios estendidos longitudinalmente; entrelaça os fios de urdume, passando o novelo de tiras entre a cala (abertura entre os fios de urdume), e na sequencia empurra a tira (trama) utilizando o pente. O tapete é tecido até o comprimento desejado; com paradas para atadura das tiras partidas, emendando-os manualmente, para obter um produto sem falhas.

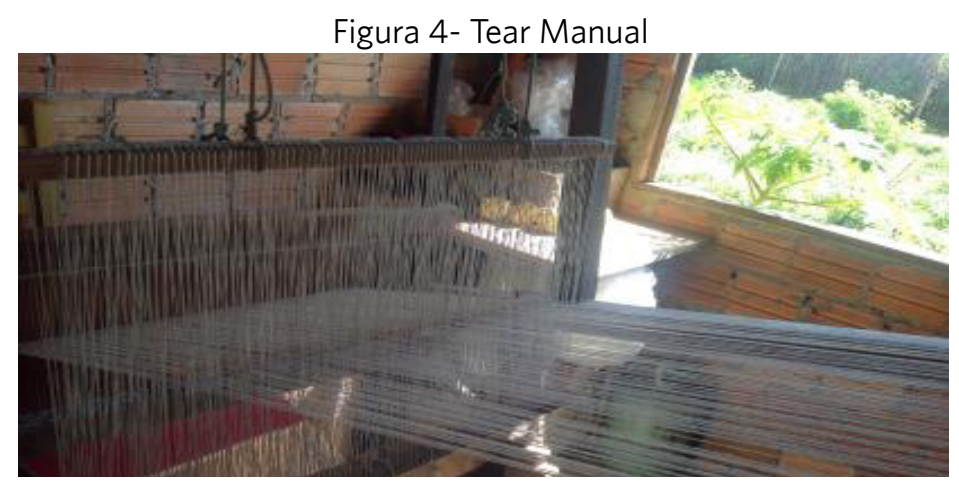

Fonte: Elaborado pelos autores, 2014

\section{Análise da tarefa}

A partir da AET- foi possível relacionar aspectos da ergonomia física que segundo International Ergonomics Association - IEA, a ergonomia física no trabalho está relacionada a fatores humanos como a antropometria, anatomia, fisiologia e biomecânica em sua relação a atividade física no trabalho. Assim configura-se como tópicos relevantes a análise da postura, manuseio de materiais, movimentos repetitivos, distúrbios musculoesqueléticos; que fazem parte da interação no momento da atividade de trabalho.

De acordo com a imagem (figura 5) é possível observar que a artesã realiza a tarefa sentada em uma cadeira. Seus pés encontram-se apoiados sob dois pedais, que servem para movimentar os quadros. Com a mão direita e esquerda, a artesã passa de forma alternada o novelo de tiras de tecido entre a cala (abertura formada pelos fios de urdume), sendo que enquanto uma mão passa o novelo à outra alternadamente puxa o quadro de liços, comprimindo a trama, e formando o tecido.

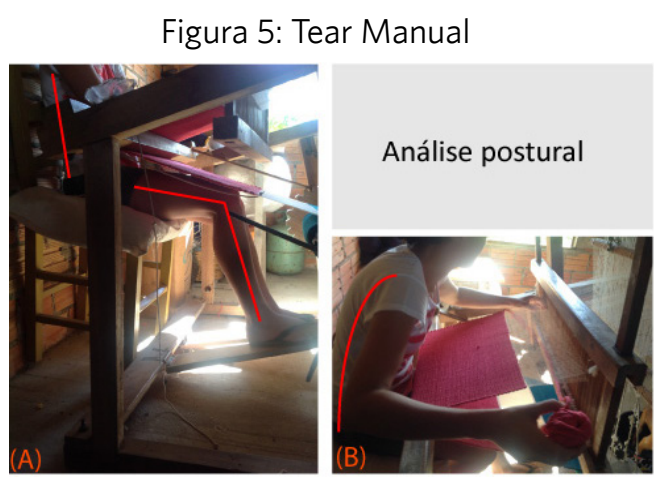

Fonte: Elaborado pelos autores, 2014

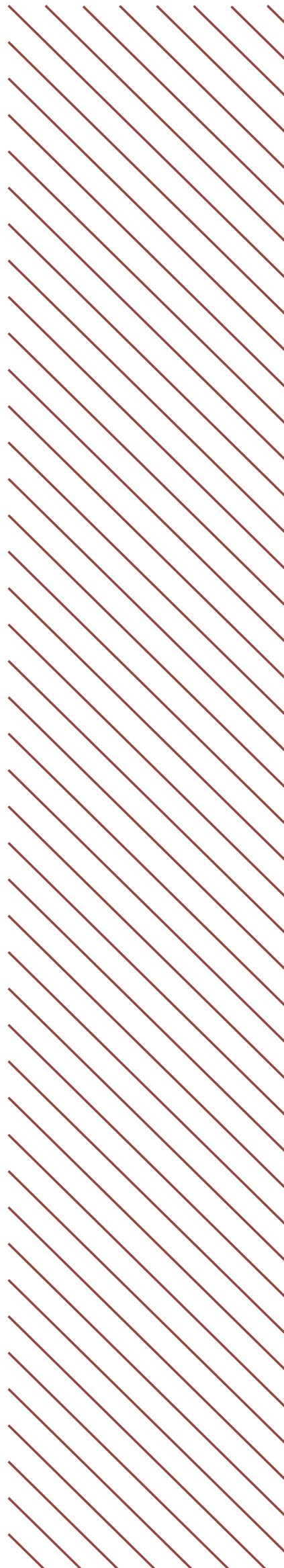


Durante a atividade de trabalho foi observado à interação do operador com o tear, assim levando em conta, a tarefa realizada com as mãos, a postura, os movimentos e deslocamentos, os olhares, iluminação, onde tais aspectos são descritos de acordo com a imagem a seguir:

Figura 6- Análise de tarefa

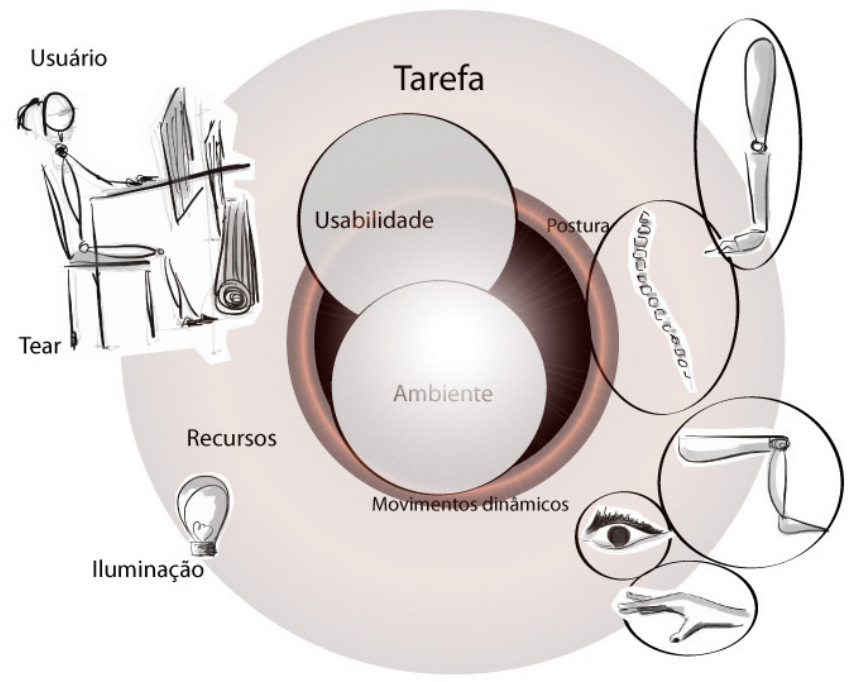

Fonte: Elaborado pelos autores, 2014

De acordo com a análise da tarefa foi possível representar a situação de trabalho que de acordo com a (figura 6) o operador e o tear estão relacionados a partir da tarefa, que se constitui como a função integradora (GUÉRIN et al., 2001), onde a partir dela é possível destacar aspectos físicos que fazem parte do ambiente de trabalho como: o espaço, a iluminação, o tear. Tais elementos em contato com o operador são analisados pelo ponto de vista da ergonomia física que de acordo com a figura 6 considera-se: os olhos, braços, pernas, mãos, coluna.

A partir da representação (figura 6) é possível estabelecer relações entre fatores humanos, ambiente e máquina (tear); para que se estruturasse uma análise dos aspectos ergonômicos de um posto de trabalho de tecelagem manual.

Quadro 2 - Aspecto físico e Ambiente

$\begin{array}{ll}\text { Coluna } & \begin{array}{l}\text { Enquanto a artesã realiza a tarefa a coluna movimenta-se } \\ \text { alternando a posição entre um eixo de } 0 \text { a } 45 \text { graus. }\end{array} \\ \text { Olhar } & \begin{array}{l}\text { O olhar acompanha a execução da tecelagem num movimento } \\ \text { acompanhado pelo pescoço em um eixo de até } 20 \text { graus }\end{array}\end{array}$




\begin{tabular}{|c|c|}
\hline Ritmo & $\begin{array}{l}\text { A cada } 30 \text { segundos a artesã realiza } 24 \text { linhas de trama, o que } \\
\text { representa um trabalho dinâmico e repetitivo. }\end{array}$ \\
\hline Iluminação & $\begin{array}{l}\text { A iluminação durante o dia ocorre pela luz que incide da janela, } \\
\text { e em dias nublados ou a noite é iluminado por uma lâmpada } \\
\text { posicionada no teto no centro do espaço de trabalho, ficando a } \\
\text { uma distância aproximada de } 3 \text { metros do tear. }\end{array}$ \\
\hline
\end{tabular}

Fonte: Elaborado pelos autores, 2014

A partir da análise da atividade foi possível levantar demandas de atividade e confrontar com o referencial teórico a fim de diagnosticar e apontar soluções operativas para uma situação de trabalho.

O quadro abaixo relaciona posturas, movimentos e fatores ambientais onde destaca níveis de usabilidade da artesã com o tear.

Quadro 3 - Demandas de atividade

\begin{tabular}{l|l|l|}
\multicolumn{2}{|c|}{ DEMANDAS DE ATIVIDADE - Tecelagem Manual } \\
\hline $\begin{array}{l}\text { Operador } \\
\text { Aspecto Físico }\end{array}$ & Referencial Teórico & Usabilidade \\
\hline $\begin{array}{l}\text { Postura com relação à } \\
\text { coluna vertebral }\end{array}$ & Dul e Weerdmeester (2004), NR 17 \\
\hline $\begin{array}{l}\text { Postura dinâmica no } \\
\text { coluna }\end{array}$ & Dul e Weerdmeester (2004), NR 17 \\
\hline $\begin{array}{l}\text { Movimento para pegar } \\
\text { o novelo }\end{array}$ & Santos e Fialho (1997), NR 17 \\
\hline $\begin{array}{l}\text { Postura dinâmica no } \\
\text { movimento dos pés }\end{array}$ & Dul e Weerdmeester (2004), NR 17 \\
\hline $\begin{array}{l}\text { Postura com relação } \\
\text { aos pés }\end{array}$ & Dul e Weerdmeester (2004), NR 17 \\
\hline $\begin{array}{l}\text { Posição das pernas } \\
\text { lluminação }\end{array}$ & Dul e Weerdmeester (2004), NR 17 \\
\hline \begin{tabular}{l} 
Legenda: \\
\hline Usabilidade Nível Bom
\end{tabular}
\end{tabular}

Fonte: Elaborado pelos autores, 2014

De acordo com Dul e Weerdmeester (2004) cadeiras operacionais devem ser projetadas de acordo com o tipo de tarefa. No caso do posto de trabalho em 
estudo a artesã usa uma cadeira rústica que não está adaptada as condições de trabalho.

Coluna: Na imagem da figura 3 (a) observa-se que a coluna não se encontra alinhada ao encosto da cadeira, sendo que este deve proporcionar apoio para a região lombar (na altura do abdômen), com um vão livre de 10 a $20 \mathrm{~cm}$ do acento.

Na cadeira o encosto é formado por três hastes horizontais, o que por um longo período de tempo poderia causar desconforto e acarretar problemas musculoesqueléticos.

A posição da cadeira por se encontrar muito próxima ao tear, também compromete a posição da coluna, de acordo com a imagem (figura 5), observase uma ligeira inclinação no corpo da artesã, evitando que a coluna alinhe-se corretamente ao encosto.

O movimento realizado na passagem do novelo por entre a cala, a artesã executa movimentos repetitivos que exigem a movimentação da coluna, mãos e braços.

Durante esse movimento a posição da mão com relação ao punho permanece numa rotação inferior a 5 graus, o que não compromete a articulações neste ponto do corpo. Porém por caracterizar-se como um movimento repetitivo que exige um alto grau de angulação da coluna, variando numa posição de 0 a 45 graus, pode por um longo período de tempo gerar um desgaste físico e dores musculoesqueléticas.

A posição dos pés com relação o pedal quando parado está numa posição de 25 graus com relação ao solo, o que indica uma postura adequada para quem está sentada (DUL; WEERDMEESTER, 2004). Durante a movimentação dos pedais exige uma flexão dos joelhos entre 5 e 45 graus, o que não indica sobrecarga nas articulações.

De acordo com a imagem observa-se que a almofada na cadeira foi um recurso que possibilitou melhor alcance para a parte superior do corpo permitindo que os braços ficassem na posição adequada para realização da tarefa.

Essa adaptação não comprometeu a posição das pernas para a movimentação do pedal, sendo que o espaço para as pernas está de acordo com as dimensões corporais da artesã, porém necessitaria de uma adequação para uma pessoa com menor ou maior estatura. 
Para a tecelagem do tapete, exige que em alguns casos a manipulação fique fora do alcance da artesã, no caso estudado a artesã executa um tapete com largura aproximada de $100 \mathrm{~cm}$ de largura, porém os tapetes produzidos nesta comunidade podem chegar a $280 \mathrm{~cm}$ de largura. De acordo com (DUL; WEERDMEESTER, 2004; SANTOS; FIALHO, 1995), partindo do ombro como ponto de referência o espaço máximo para manipulação não deve ultrapassar a um raio aproximado de $50 \mathrm{~cm}$, o que em um tapete de maior largura exigiria a inclinação do corpo, que em uma longa jornada acarretaria em um maior desgaste físico.

Durante a execução da tarefa, além do manejo do quadro de liças e do novelo, a artesã a cada $40 \mathrm{~cm}$ de tecelagem, necessita enrolar o rolo que se encontra abaixo do tear.

Dependendo do comprimento do tapete tecido, necessita de maior esforço das mãos para girar o rolo, o que por um longo período de tempo poderia causar fadiga muscular e lesões esqueléticas.

Com relação à visão, observou-se que o tear por encontrar-se próximo a uma janela oferece alta iluminação no ponto de visualização da artesã, sendo que em dias nublados ou escuros, a iluminação artificial não oferece luz necessária. Nesse sentido tanto a baixa como a alta iluminação afetam a acuidade do trabalho, bem como provocam um esforço físico podendo ao longo de um período provocar cansaço e desconforto.

\section{Resultados}

A partir desse estudo foi possível identificar demandas existentes em uma situação de trabalho relacionadas à forma de interação do operador com o tear, assim destacando-se pontos que poderiam afetar a saúde, bem como provocar desconfortos durante e após a execução da tarefa.

Com a análise foi possível propor melhorias nas condições de trabalho, que estão ligadas aos aspectos da usabilidade do tear, como:

A utilização de uma cadeira operacional que possibilite uma posição correta da coluna, com regulagem para altura do acento, com pés que encaixam no tear possibilitando uma maior aproximação do corpo. Estofamento firme no encosto e acento também proporcionaria maior conforto.

Pontos de iluminação artificial distribuídos no espaço de trabalho posicionadas de modo que evitem o reflexo, sendo que para essa mudança são necessárias adequações de acordo com o posicionamento do tear.

Também como uma solução incremental aponta-se uma regulagem para 
altura do tear o que possibilite uma maior equidade no uso (figura 7).

Figura 7- proposta ergonômica

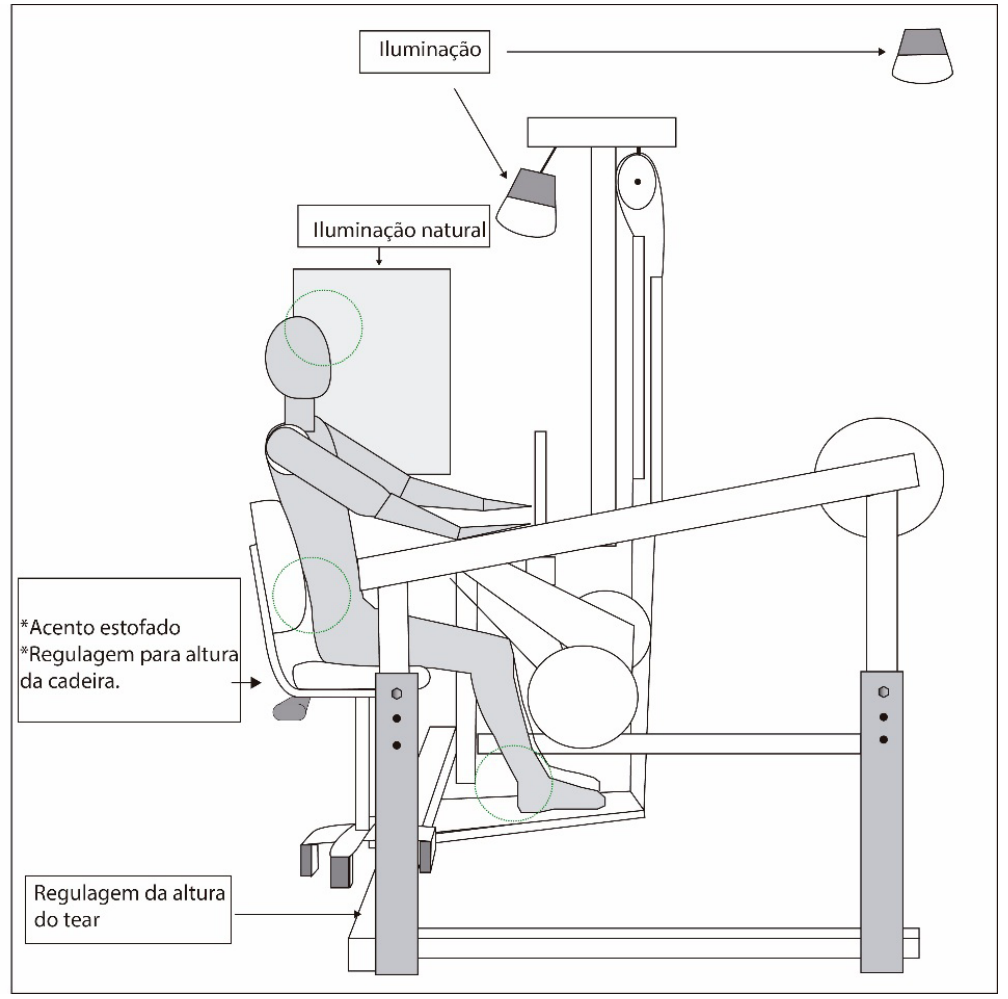

Fonte: Elaborado pelos autores, 2014

Este estudo encontrou limitações no que se refere às soluções de nível técnico nas quais o design em participação com áreas como a engenharia poderia propor, como por exemplo; adaptações ao tear com apoio mecânico para movimentar o rolo que certamente melhorariam o desempenho tanto do ponto de vista da produtividade como da qualidade de vida do trabalhador, porém tais incrementos neste caso são questionáveis considerando aspectos culturais que devem ser preservados, como o tear enquanto um artefato manual.

Alguns aspectos que podem afetar a saúde do operador, como tarefa repetitiva, neste estudo foram observados que a artesã executa outras atividades na sua jornada de trabalho como alimentação do tear, amarração do tapete. Tais atividades possibilitam a adequação do ritmo de trabalho de acordo com as condições e predisposições diárias, o que proporciona um enriquecimento da tarefa, tornando o trabalho menos repetitivo evitando a fadiga e proporcionando qualidade na saúde do corpo e mente do trabalhador.

Martins e Merino (2011, p. 55) aponta que "seres humanos em equilíbrio à vida são seres mais criativos, capazes e principalmente motivados", onde o fato de estarem em um ambiente familiar proporciona qualidade de vida para o 
trabalhador.

\section{CONCLUSÃO}

Neste estudo a ergonomia foi tratada a ponto de que se pudesse compreender no contexto de uma comunidade criativa de tecelagem a relação homem-máquina, modo que contribuísse com o processo de identificação de demanda necessária para soluções incrementais na usabilidade do tear.

A representação do sistema, bem como de seus elementos facilitou a identificação das características ambientais, das estruturas envolvidas na tarefa, e aspectos ligados as limitações do corpo humano. Neste estudo a ergonomia teve um papel importante, aproximando as estruturas, bem como de forma sistemática, compreendendo as relações que aqui foram tratados como trabalho.

Isso implica em dizer que a ergonomia e o design são disciplinas complementares, onde ambas têm papel ativo na qualidade na interação humana seja por meio da relação homem-máquina, visto pelo ponto de vista da ergonomia; seja pelo ponto de vista do homem enquanto usuário.

Também sobre a relação entre a ergonomia e o design, mostra-se útil a abordagem sistêmica que possibilitou a aproximação entre essas duas áreas, que como no estudo foi aplicada a um micro sistema, aqui tratado pela situação de trabalho; porém tal abordagem torna-se útil para a expansão da compreensão da organização como um todo, possibilitando a identificação de competências vistas pelo ponto de vista técnico, bem como para evidenciar valores que certamente propiciam melhorias no trabalho e no modo de vida de comunidades criativas.

\section{REFERÊNCIAS}

BERTALANFFY, Ludwig Von. Teoria geral dos sistemas. 3. ed. Petrópolis: Vozes, 2008.

HEALTH AND SAFETY EXECUTIVE. Bureau of Labor Statistics. Workplace In juries and IIInesses- 2012. U.S. DepartmentofLabor'sOccupationalSafetyand Health Administration 2013. Disponível em: <http://www.bls.gov/news. release/osh.nrO.htm>. Acesso em: 28 mar. 2014.

BONSIEPE, G.; DUTRA, C. Design: do material ao digital. Florianópolis: FIESC/ IEL, 1997. 
CARLI, A. M. S. et. al. Design e artesanato: novidade e tradição, um diálogo possível. Redige, v. 2, n. 2, p. 430-444, 2011.

\section{CONSELHO NACIONAL DO AMBIENTE E DO DESENVOLVIMENTO} SUSTENTÁVEL. Comentário do CNADS sobre o "Relatório de Factores Críticos da Avaliação Ambiental Estratégica" das propostas [...] e Directiva Europeia 2001/42/CE. Disponível em:<http://www.cnads.pt/ index.php?option=com docman\&task=cat_view\&gid=52\&ltemid=84>. Acesso em: 12 ago. 2014.

DUL, J.; WEERDMEESTER, B. Ergonomia na prática. Tradução Itirollda. São Paulo: Edgard Blücher, 2004.

GOMES FILHO, J. Design do objeto: bases conceituais. São Paulo: Escrituras, 2006.

GUÉRIN, F. et al. Compreender o trabalho para transformá-lo: a prática da ergonomia. São Paulo: Edgard Blücher: Fundação Vanzolini, 2001.

INTERNATIONAL ERGONOMICS ASSOCIATION. Definition and Domains of ergonomics. Disponível em:<http://www.iea.cc/whats/index.html>. Acessado em: 28 mar. 2014.

JORDAN, P. W. et al. Usability evaluation in industry. London: Taylor \& Francis, 1996

KRUCKEN, L. Design e território: valorização de identidades e produtos locais. São Paulo: Studio Nobel, 2009.

LANDIM, P.D.C. Design, empresa, sociedade. São Paulo: Cultura Acadêmica, 2010

MANZINI, E. Design para a inovação social e sustentabilidade: comunidades criativas, organizações colaborativas e novas redes projetuais. 2008.

Disponível em:<http://www.e-papers.com.br>. Acessado em: 1 ago. 2014.

MARTINS, R. F. F; MERINO, E. A. D. Gestão de Design como estratégia organizacional. 2. ed. Londrina: EDUEL, 2011.

MERINO, E. A. D. Fundamentos da ergonomia. Florianópolis: UFSC, 2011. Apostila.

MERONI, A. Creative Communities: People inventing sustainable way sof living. Milano: Edizioni Polidesign, 2007. 
ORGANIZAÇÃO DAS NAÇÕES UNIDAS. Declaração do Rio sobre Meio Ambiente e Desenvolvimento. 1992. Disponível em:<http://www.onu.org.br/ rio20/para-alem-do-pib-pnud-propoe-indice-de-desenvolvimento-humanosustentavel/.> Acesso em: 28 mar. 2014.

PASCHOARELLI, L.C; MENEZES, M.S. (Org.). Design: questões de pesquisa. Rio de Janeiro: Rio Book's, 2010.

\section{PIZO, C. A.; MENEGON, N.L. Análise ergonômica do trabalho e o} reconhecimento científico do conhecimento gerado. Produção, v.20, n.4, out/ dez. 2010. Disponível em: <http://prod.org.br/files/v20n4/v20n4a12.pdf>. Acesso em: 1 ago. 2014

RODRIGUES, R.F.; MERINO, E.A.D.; CASAROTTO FILHO, N. Contribuição da ergonomia no processo de inovação das instituições. Ação Ergonômica, v. 8, n.1, p. 24-32, 2013. Disponível em:<http://www.abergo.org.br/revista/index.php/ ae/issue/view/19>. Acesso em:28 mar. 2014.

SALDANHA, M. C. W. et al. Ergonomia e sustentabilidade na atividade jangadeira: construção das demandas ergonômicas na praia de Ponta Negra - RN. Ação Ergonômica, v. 7, n.1, p. 101-121, 2012 . Disponível em:<http://www. abergo.org.br/revista/index.php/ae/ article/view/133>. Acesso em: 28 mar. 2014.

SANTOS, N.; FIALHO, F. A. P. Manual de Análise Ergonômica no Trabalho. Curitiba: Gênesis Editora, 1995.

STANTON, N. A.; BARBER, C. Factors affecting the selection of methods and techniques prior to conducting a usability evaluation. In: JORDAN, P. W. et al. Usability evaluation in industry. London: Taylor \& Francis, 1996. p. 39-48.

STANTON, N. A. Human in Factors in Consumer Products. Bristol: CRC Press, 2003. 